\title{
COMPARISON OF VHF, RF AND DC PLASMA EXCITATION FOR a-Si:H DEPOSITION WITH HYDROGEN DILUTION
}

\author{
R. PLATZ, C. HOF ${ }^{\ddagger}, \mathrm{S} . \mathrm{WIEDER}^{\dagger}, \mathrm{B} \cdot \mathrm{RECH}^{\dagger}, \mathrm{D} \cdot \mathrm{FISCHER}{ }^{\ddagger}, \mathrm{A} \cdot \mathrm{SHAH}{ }^{\ddagger}$, \\ A. PAYNE and S. WAGNER \\ Department of Electrical Engineering, Princeton University, Princeton, NJ 08544, USA \\ ¥ Institut de Microtechnique, Université de Neuchâtel, Switzerland \\ ${ }^{\dagger}$ Institut für Schicht- und Ionentechnik - PV, Forschungszentrum Jülich, Germany
}

\begin{abstract}
A comparative study of DC, RF and VHF excitation for the plasma enhanced chemical vapor deposition (PECVD) of intrinsic layers of a-Si:H is presented, with special emphasis on the effects of hydrogen dilution. Growth rates at comparable plasma power, for substrate temperatures between $100^{\circ} \mathrm{C}$ and $300^{\circ} \mathrm{C}$ and for various $\mathrm{H}_{2}$ dilution ratios are presented, along with optical bandgap, $\mathrm{H}$ content, and electronic transport properties in the light-soaked state.

$\mathrm{H}_{2}$ strongly reduces the growth rate for all techniques. The growth rate for the highest $\mathrm{H}_{2}$ dilution ratio is approximately four times higher for VHF than for DC or RF excitation. In all three cases increasing the substrate temperature reduces the optical gap and the $\mathrm{H}$ content $\mathrm{C}_{\mathrm{H}}$. Raising the substrate temperature slightly enhances the stability of undiluted films. $\mathrm{H}_{2}$ dilution increases the optical gap for all three techniques. The $\mathrm{H}$ content of RF- and VHF-deposited samples increases with increasing $\mathrm{H}_{2}$ dilution ratio, while in DC deposition it produces an initial drop of the $\mathrm{H}$ content, followed by an increase.

In all three cases, $\mathrm{H}_{2}$ dilution improves the electronic transport properties of the material by roughly a factor of two. The gain in stability is most pronounced for relatively small dilution; in the case of DC deposition, too strong a dilution even has an adverse effect on stability.
\end{abstract}

\section{INTRODUCTION}

Since the first observation of enhanced stability of a-Si:H films deposited with $\mathrm{H}_{2}$ dilution [1] this technique has become the only tool available at the production level proven to result in a-Si:H solar cells with improved stability against light-soaking. However, the proper choice of plasma excitation frequency in combination with $\mathrm{H}_{2}$ dilution has not yet been resolved satisfactorily.

In the present paper, we directly compare standard radio frequency (RF, $13.56 \mathrm{MHz}$ ) deposition to very high frequency (VHF) deposition at $70 \mathrm{MHz}$ and deposition using a direct current (DC) excitation, all with special emphasis on the influence of $\mathrm{H}_{2}$ dilution. All three methods have shown potential for producing solar cells with high stabilized efficiency (e.g., [2,3] for RF, [4] for VHF and [5] for DC).

\section{EXPERIMENTS}

Three different deposition systems were used for the deposition of the a-Si:H films. Each of the three systems was built and optimized for a given excitation frequency. The DC-deposited films were made in the i-chamber of a three-chamber PECVD system with load-lock at Princeton. We also deposited a few layers using RF excitation in this reactor (referred to as $\mathrm{RF}(\mathrm{P})$ ). All other intrinsic layers using RF excitation were deposited in the i-chamber of a threechamber system with load-lock at Jülich. Depositions using the VHF excitation technique at 
$70 \mathrm{MHz}$ were performed in a load-locked single chamber reactor at Neuchâtel, designed especially for the VHF-GD technique. Table 1 gives an overview of the deposition conditions used for the three techniques.

\begin{tabular}{|c|c|c|c|c|c|c|}
\hline & $\begin{array}{c}\text { Electrode } \\
\text { dimensions }\end{array}$ & $\begin{array}{c}\text { Electrode } \\
\text { area } \\
{\left[\mathrm{cm}^{2}\right]}\end{array}$ & $\begin{array}{c}\text { El.-substr. } \\
\text { distance } \\
{[\mathrm{cm}]}\end{array}$ & $\begin{array}{c}\text { Pressure } \\
\text { undiluted } \\
\text { films [mbar] }\end{array}$ & $\begin{array}{c}\text { Pressure } \\
\text { diluted films } \\
{[\mathrm{mbar}]}\end{array}$ & $\begin{array}{c}\text { Power } \\
\text { density } \\
{\left[\mathrm{mW} / \mathrm{cm}^{2}\right]}\end{array}$ \\
\hline DC & $15 \times 15 \mathrm{~cm}^{2}$ & 225 & 1.6 & 0.67 & 0.93 & $44\left(\times^{1} / 2\right)$ \\
\hline RF & $\varnothing 13.5 \mathrm{~cm}^{2}$ & 143 & 1.2 & 1.33 & 2.66 & 30 \\
\hline RF(P) & $15 \times 15 \mathrm{~cm}^{2}$ & 225 & 1.6 & 0.67 & - & 22 \\
\hline $\mathrm{VHF}$ & $\varnothing 13.0 \mathrm{~cm}$ & 133 & 1.6 & 0.35 & 0.5 & 30 \\
\hline
\end{tabular}

Table 1: Geometrical dimensions of the electrodes, and deposition conditions.

The temperatures given throughout this work are true substrate temperatures, determined by calibration for conditions corresponding to those during deposition. The plasma excitation power was chosen to be comparable in all three cases. For the DC-deposited films, the plasma burns towards both sides of the powered electrode, due to the triode-configuration of the reactor. The effective electrode surface is therefore doubled. The value of $44 \mathrm{~mW} / \mathrm{cm}^{2}$ given in the table is the value of the input power divided by the single electrode surface. The input power given for RF and VHF deposition was measured by a power meter between the generator and the matching network, and the value for DC deposition is given by current and voltage of the discharge.

Corning 7059 glass, and crystalline silicon substrates for infrared (IR) spectroscopy, were used in parallel for all depositions.

The optical absorption coefficient was measured by transmission, and $\mathrm{C}_{\mathrm{H}}$ by integration of the $640 \mathrm{~cm}^{-1}$ absorption peak in the IR absorption spectrum, using $\mathrm{C}_{\mathrm{H}}[$ at. $\%]=2.1 \cdot 10^{19} \mathrm{~cm}^{-2} / 5 \cdot 10^{22} \mathrm{~cm}^{-3} \int \alpha(\omega) / \omega \mathrm{d} \omega$.

DC- and VHF-deposited films were degraded to saturation by a combination of pulsed dye laser degradation and HeNe laser illumination [6]. The transport properties were characterized using the mobility-lifetime product $\mu_{0} \tau_{0}$, which combines information on the majority carriers (from photo-conductivity measurements) and the minority carriers (from the steady-state photocarrier grating, SSPG, technique); $\mu_{0} \tau_{0}$ correlates with the performance of a-Si:H p-i-n solar cells [7]. RF-deposited films were light-soaked for $600 \mathrm{~h}$ using $100 \mathrm{~mW} / \mathrm{cm}^{2}$ white light and characterized by photo-conductivity and constant photo-current method (CPM) measurements [3].

\section{GROWTH RATE}

The growth rate of the a-Si:H films is plotted in Figure 1 as a function of the $\mathrm{H}_{2}$ dilution ratio $\left(=\left[\mathrm{H}_{2}\right] /\left[\mathrm{SiH}_{4}\right]\right)$ for the three excitation techniques and a substrate temperature of $\sim 200^{\circ} \mathrm{C}$. For undiluted films, VHF deposition yields the highest growth rate of over $4 \AA / s$; however, the growth rate obtained with DC excitation is only slightly lower. The growth rate of RF-deposited films without $\mathrm{H}_{2}$ dilution is $\sim 2 \AA / \mathrm{s}$. The influence of $\mathrm{H}_{2}$ dilution is quite different for the three excitation frequencies. We observe a roughly linear dependence of the growth rate on the $\mathrm{H}_{2}$

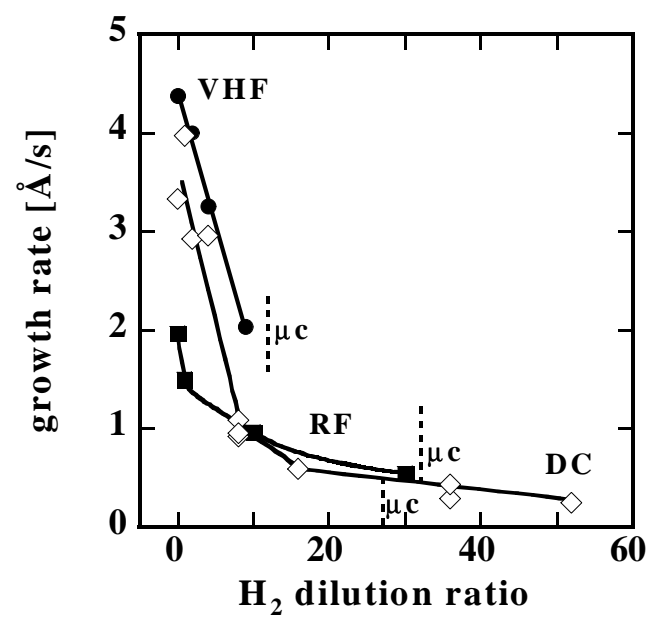

Figure 1: Growth rate for VHF, RF and $D C$ deposition as a function of the $\mathrm{H}_{2}$ dilution ratio $\left(=\left[\mathrm{H}_{2}\right] /\left[\mathrm{SiH}_{4}\right]\right)$. Input power is $30 \mathrm{~mW} / \mathrm{cm}^{2}$ (VHF, RF) and $44\left(\times^{1} / 2\right) \mathrm{mW} / \mathrm{cm}^{2}(D C) . T_{s} \sim 200^{\circ} \mathrm{C}$. 
dilution ratio in the case of VHF excitation. The range of $\mathrm{H}_{2}$ dilution is very limited for the VHF technique as microcrystalline growth starts already at a dilution ratio of $\sim 12$. Above $200^{\circ} \mathrm{C}$ microcrystalline growth sets in at even lower $\mathrm{H}_{2}$ dilution ratios. The RF growth rate is lower and also a smooth function of $\mathrm{H}_{2}$ dilution. Microcrystalline growth sets in at dilution ratios exceeding 30. The growth rate of the DCdeposited films drops by a factor of three between $\mathrm{H}_{2}$ dilution ratios of zero and eight, almost parallel to VHF deposition. More $\mathrm{H}_{2}$ in the plasma reduces the growth rate further, but with a smaller slope and similar to RF deposition. We observe the onset of microcrystalline growth at $190^{\circ} \mathrm{C}$ for $\mathrm{H}_{2}$ dilution ratios of $\leq 30$. We conclude that VHF clearly favors microcrystalline growth, which starts at very low $\mathrm{H}_{2}$ dilution ratios. DC and RF deposition both require much higher $\mathrm{H}_{2}$ dilution ratios to yield microcrystals. The amount of $\mathrm{H}_{2}$ dilution to obtain microcrystalline films appears lower for DC than for RF excitation.

\section{OPTICAL GAP AND HYDROGEN CONTENT}

Influence of the substrate temperature

In all three cases the substrate temperature has a relatively small influence on the growth rate. The growth rate increases slightly with increasing substrate temperature and at any temperature follows the same dependence on the $\mathrm{H}_{2}$ dilution ratio as plotted in Figure 1. The optical gap and the material properties of the a-Si:H films, in contrast, are strongly influenced by the substrate temperature. We varied the substrate temperature between $\sim 100^{\circ} \mathrm{C}$ and $\sim 300^{\circ} \mathrm{C}$. The optical gap of intrinsic a-Si:H films deposited without $\mathrm{H}_{2}$ dilution decreases approximately linearly with increasing substrate temperature (Figure 2a) for all three excitation techniques.

The decrease in the optical gap of the a-Si:H films correlates with a decrease in the $\mathrm{H}$ content in the films (Figure 2b). $\mathrm{C}_{\mathrm{H}}$ is an approximately linear function of the substrate temperature in the investigated temperature range. All excitation frequencies yield comparable values for the optical gap and the H content.

\section{$\underline{\text { Influence of hydrogen dilution }}$}

The influence of $\mathrm{H}_{2}$ dilution depends on the excitation frequency. In all three cases, the optical gap $\mathrm{E}_{04}$ increases with $\mathrm{H}_{2}$ dilution (Figure $3 \mathrm{a}$ ). For VHF and $\mathrm{RF}$ excitation techniques, the increase is monotonic and almost linear. In the case of $\mathrm{RF}$ excitation, a $\mathrm{H}_{2}$ dilution ratio of 30 results in approximately the same increase in $\mathrm{E}_{04}$ as a dilution of ten for VHF $(\sim 0.05-0.1 \mathrm{eV})$. 
DC deposition exhibits a different response to $\mathrm{H}_{2}$ dilution. For low $\mathrm{H}_{2}$ dilution ratios, the optical gap increases moderately and similarly to VHF and RF. Between a dilution ratio of four and six, however, the increase in the optical gap is very steep, followed by an increase to $>2.05 \mathrm{eV}$ with further dilution. Sub-bandgap absorption spectra and UV reflectance measurements [8] indicate that these samples still are purely amorphous.

The $\mathrm{H}$ content of the RF and VHF films increases with increasing $\mathrm{H}_{2}$ dilution ratio (Figure $3 b)$. The increase in $C_{H}$ is much more pronounced for the VHF than for the RF samples, and $\mathrm{C}_{\mathrm{H}}$ exceeds 20 at.\% for the highest dilution. However, we find again for both, RF- and VHFdeposited samples, a correlation between the optical gap and the $\mathrm{H}$ content.

The DC samples exhibit an anomaly in the influence of $\mathrm{H}_{2}$ dilution on the $\mathrm{H}$ content. The optical gap increases with $\mathrm{H}_{2}$ dilution, though not monotonically. The $\mathrm{H}$ content, in contrast, initially decreases and reaches a minimum at a $\mathrm{H}_{2}$ dilution ratio of $\sim 4$. For still higher $\mathrm{H}_{2}$ dilution ratios the $\mathrm{H}$ content increases as it does for VHF and RF deposition. Bennett et al. [9] also reported a decrease in the $\mathrm{H}$ content and a moderately increased optical gap for DC samples deposited with $\mathrm{H}_{2}$ dilution ratios of up to ten.

\section{TRANSPORT PROPERTIES AND STABILITY}

The primary goal of $\mathrm{H}_{2}$ dilution is to enhance the stability of a-Si:H against light-induced degradation.

Figure 4 shows the $\mu_{0} \tau_{0}$ product in the degraded state for VHF-deposited samples as a function of the $\mathrm{H}_{2}$ dilution ratio for deposition temperatures between $195^{\circ} \mathrm{C}$ and $280^{\circ} \mathrm{C}$. The $\mu_{0} \tau_{0}$ product for samples deposited without $\mathrm{H}_{2}$ dilution improves slightly with increasing substrate temperature, and considerably with $\mathrm{H}_{2}$ dilution. $\mathrm{A} \mathrm{H}_{2}$ dilution ratio of two raises $\mu_{0} \tau_{0}$ by a factor of two. A further increase in the $\mathrm{H}_{2}$ dilution ratio does not raise $\mu_{0} \tau_{0}$, whereas the optical gap continues to increase.

In RF-deposited films (Figure 5), higher deposition temperatures similarly result in higher photo-conductivity and lower defect density in the degraded state for films deposited without $\mathrm{H}_{2}$ dilution. $\mathrm{H}_{2}$ dilution also raises $\sigma_{\mathrm{ph}}$ and reduces the defect density, both by up to a factor of 2-3. The improvement is more pronounced for samples deposited at lower temperature. The material quality continuously increases with increasing $\mathrm{H}_{2}$ dilution, even though most of the improvement is achieved already for a $\mathrm{H}_{2}$ dilution ratio of ten.

Likewise, the stabilized $\mu_{0} \tau_{0}$ product in the DC films improves with increasing substrate temperature (Figure 6). $\mathrm{H}_{2}$ dilution has a beneficial effect at low dilution ratios: the degraded $\mu_{0} \tau_{0}$ product is roughly a factor of two higher for samples deposited with a dilution ratio of 2-4 


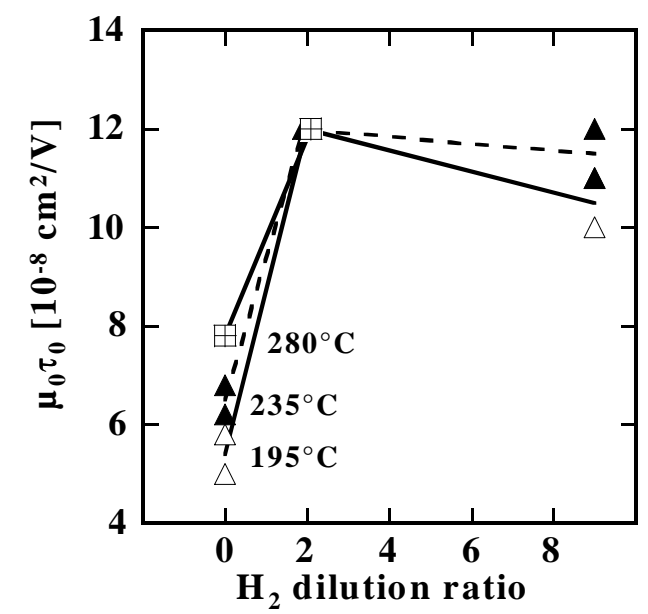

Figure 4: $\mu_{0} \tau_{0}$ product in the degraded state for VHF-deposited films as a function of the $\mathrm{H}_{2}$ dilution ratio.

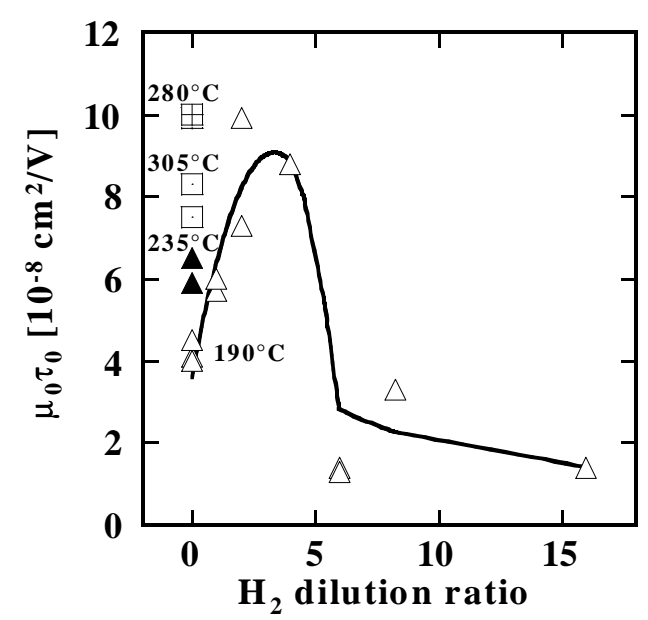

Figure 6: $\mu_{0} \tau_{0}$ product in the degraded state for DC-deposited films as a function of the $\mathrm{H}_{2}$ dilution ratio.

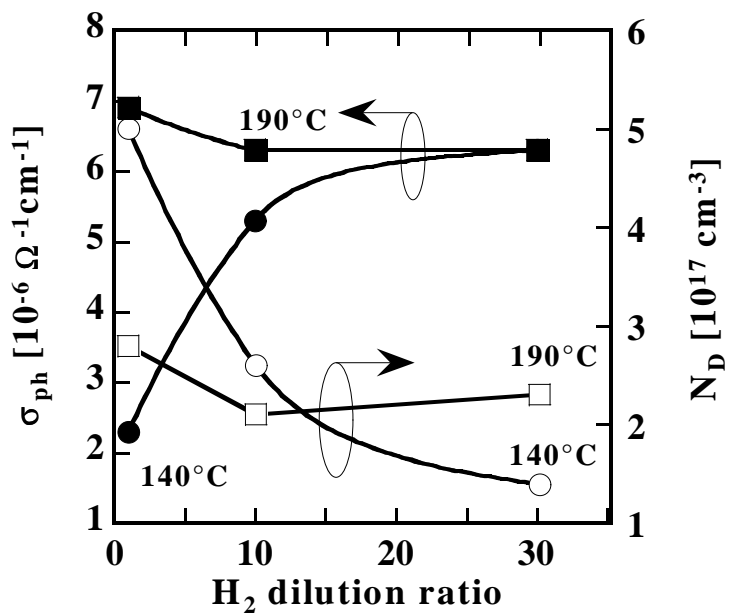

Figure 5: Defect density and photoconductivity values in the degraded state for $R F$-deposited films as a function of the $\mathrm{H}_{2}$ dilution ratio [3].

than for undiluted films, which is comparable to the improvement achieved for VHF-deposited samples (Figure 4). For high dilution ratios, in contrast to the observations for VHF and RF deposition, the quality of the films decreases again, even to below the value for undiluted films. It is interesting to note that the improvement of the stability correlates with the decrease in the hydrogen content (Figure $3 b$ ) for small $\mathrm{H}_{2}$ dilution ratios. In the case of DC excitation, material with enhanced stability is therefore equivalent to material containing less hydrogen, whereas for RF and VHF deposition the gain in stability is achieved for material containing more hydrogen than material deposited without $\mathrm{H}_{2}$ dilution.

\section{DISCUSSION}

$\mathrm{H}_{2}$ dilution enhances the electronic transport properties of a-Si:H in the light-soaked state for all the investigated excitation methods. For the DC deposition technique we observe an optimum $\mathrm{H}_{2}$ dilution ratio whereas VHF and $\mathrm{RF}$ exhibit a pronounced improvement for small $\mathrm{H}_{2}$ dilutions followed by a rather small additional effect for still higher $\mathrm{H}_{2}$ dilution ratios. For application as an intrinsic layer in a-Si:H solar cells, the stability of the material is only one issue. All three excitation techniques result in a more or less pronounced increase in the optical gap of a-Si:H deposited with $\mathrm{H}_{2}$ dilution. This in turn requires thicker i-layers to obtain a given current density, thus affecting the stability of the device. However, this effect is an advantage for the thin a-Si:H top cells in tandem or triple junctions. For these wide-gap cells the necessary thickness adjustment is generally small, resulting in an overall efficiency gain from the enhanced stability coupled with the higher $\mathrm{V}_{\text {oc }}$ that results from the higher optical gap of the i-layer. In other applications, such as in the top cell of a micromorph tandem cell [10] the increase in the optical gap due to $\mathrm{H}_{2}$ dilution is unwanted and undiluted i-layers are required [11]. 
The reduced growth rate under $\mathrm{H}_{2}$ dilution may become an important issue in industrial production. For VHF deposition we observe the best stabilized electronic properties for a $\mathrm{H}_{2}$ dilution ratio of two $(\sim 4 \AA / s)$. DC deposition yields comparable values for the degraded $\mu_{0} \tau_{0}$ product for a $\mathrm{H}_{2}$ dilution ratio of four $(\sim 2.9 \AA / \mathrm{s})$. RF deposition yields considerably lower growth rates $\left(\sim 1 \AA / \mathrm{s}\right.$ at a $\mathrm{H}_{2}$ dilution ratio of ten and $\sim 0.5 \AA / \mathrm{s}$ at a dilution of 30$)$. Therefore, as intrinsic a-Si:H material of more or less equal quality can be obtained by all three deposition techniques, the growth rate may become the decisive factor for the choice of excitation frequency.

\section{CONCLUSIONS}

Hydrogen dilution is a well-suited tool to all three excitation techniques, DC, RF and VHF, for obtaining a-Si:H with improved stability. $\mathrm{H}_{2}$ dilution results in an increase in the optical gap for all three techniques. The hydrogen content of RF- and VHF-deposited samples increases with increasing $\mathrm{H}_{2}$ dilution ratio. DC deposition with increasing $\mathrm{H}_{2}$ dilution first lowers and then raises the hydrogen content. Raising the substrate temperature in all three cases reduces the optical gap and the $\mathrm{H}$ content. The stability of samples deposited at higher substrate temperature is slightly enhanced.

In all three cases of excitation, the electronic quality of light-soaked material is improved by roughly a factor of two upon $\mathrm{H}_{2}$ dilution. Optimum $\mathrm{H}_{2}$ dilution ratios are 4 for DC, 10-30 for $\mathrm{RF}$ and $\sim 2$ for VHF excitation. $\mathrm{H}_{2}$ dilution strongly reduces the growth rate for all techniques. The growth rate for the best VHF-deposited material is $\sim 4 \AA / s$, which is $35 \%$ higher than for the equivalent DC-deposited sample (2.9 ̊/s), and 4-8 times the value for the best RF-deposited film $(0.5-1 \AA / s)$.

\section{ACKNOWLEDGEMENTS}

R. Platz thanks the Arthur u. Aenne Feindt Stiftung, Hamburg (Germany), the Fondation Charles-Edouard Guillaume, Bienne (Switzerland), and the Electric Power Research Institute for providing support for his stay at Princeton University. The authors thank S. Dubail for his technical assistance, as well as C. Beneking and F. Siebke for helpful discussions.

\section{REFERENCES}

1 S. Guha, K.L. Narasimhan and S.M. Pietruszko, J. Appl. Phys. 52 (1981) 859.

2 S. Guha, Proc. 25th IEEE PVSC (1996) 1017.

3 B. Rech, S. Wieder, F. Siebke, C. Beneking, H. Wagner, MRS Symp. Proc. 420 (1996) 33.

4 R. Platz, D. Fischer, S. Dubail and A. Shah, Solar Energy Materials and Solar Cells 46 (1997) 157.

5 L. Yang, M. Bennett, L. Chen, K. Jansen, J. Kessler, Y. Li, J. Newtown, K. Rajan, F. Willing, R. Arya, D. Carlson, MRS Symp. Proc. 420 (1996) 839.

6 C. Hof, Y. Ziegler, R. Platz, N. Wyrsch and A. Shah, Proc. ICAMS-7 (Budapest 1997), in print.

7 N. Beck, N. Wyrsch, C. Hof and A. Shah, J. Appl. Phys. 79 (1996) 9361.

8 T.I. Kamins, Polycrystalline silicon for integrated circuit applications, Kluwer Academic Publishers 1988, p.68.

9 M. Bennett, K. Rajan, K. Kritikson, Proc. 23rd IEEE PVSC (1993) 845.

10 R. Platz, J. Meier, D. Fischer, S. Dubail, A. Shah, MRS Symp. Proc. 467 (1997) 699.

11 R. Platz, C. Hof, D. Fischer, J. Meier, A. Shah, Solar Energy Materials and Solar Cells, in print. 